\title{
Fractional laser therapy - the next step in alleviating the symptoms of skin aging (own observations)
}

\author{
Adam Halbina ${ }^{1,2}$, Ewa Trznadel-Grodzka ${ }^{1,2}$, Helena Rotsztejn ${ }^{2,3}$ \\ ${ }^{1}$ Department of Dermatology and Pediatric Dermatology, Medical University of Lodz, Lodz, Poland \\ ${ }^{2}$ Dermed Medical Center, Lodz, Poland \\ ${ }^{3}$ Department of Cosmetology and Esthetic Dermatology, University of Lodz, Lodz, Poland
}

\begin{abstract}
Skin aging is a natural process of the skin, which accelerates in menopause and is additionally intensified by accumulating effects of repeated exposure to solar UV radiation and other external factors. Anti-aging skin treatment and constant improvement of its methods have become an important area of current research.

The need to apply effective skin anti-aging methods that minimize traumatization resulted in the development of fractional laser technology delivering a laser beam to microscopic column skin zones in order to achieve skin photo-remodeling.
\end{abstract}

Key words: skin aging, menopause, fractional lasers.

The process of natural skin aging tends to significantly accelerate in menopause and is additionally intensified by accumulating effects of repeated exposure to solar UV radiation and other external factors. The skin turns wrinkled, dry, thin, inelastic and contains hyperpigmentation spots. Decrease in the thickness of the epidermis and the number of eccrine glands, sebaceous gland hypertrophy, decreased number of fibroblasts and accumulation of abnormal elastin known as elastosis are visible in the histopathological image. Dysplastic lesions in the epidermal cells can also occur [1, 2].

Skin rejuvenation procedures and constant improvement of methods connected with this subject have become considerable fields of scientific research. The need for effective methods of skin photorejuvenation with minimized traumatization resulted in the development of fractional laser technology. The concept of fractional laser technology involves exposure to a microscopic laser beam 100-300 $\mu \mathrm{m}$ in diameter: Micro Epidermal Necrotic Debris (MEND) in the case of ablative lasers or Micro Thermal Zones (MTZ) for nonablative lasers [3, 8] (Figs. 1 and 2).

A laser is a device emitting an intensive, coherent and monochromatic light in a constant or pulsed way. An impulse of proper wavelength that lasts shorter than the period of thermal relaxation of the target tissue makes it possible to act in a precisely defined area without damaging the surrounding tissues [4].

In photorejuvenation procedures the water contained in the skin and collagen are the skin chromo- phores that absorb most of the emitted energy. In general, laser fractional skin rejuvenation can be divided into ablative, with vaporization of the epidermis and possibly the upper layers of the dermis (MEND), where the depletion is filled by collagen fibers from the surrounding undamaged areas, and non-ablative, with controlled overheating of tissues (MTZ). The temperature of the overheated area reaches $55-56^{\circ} \mathrm{C}$, which results in reduced tension caused by the constriction of the cruciate ligaments between spirally twisted polypeptide chains creating collagen fibers. New collagen is produced at the same time as the ongoing skin regeneration takes place in areas subjected to laser, which was confirmed in histopathological examinations. The epidermis desquamates superficially after a few days of erythema and edema of the tissue. Skin tension improves, skin surface turns smoother and color becomes more uniform. The facial skin is most frequently subjected to the procedure, but the neck, neckline and dorsal surface of hands are also common localizations. While preparing for the procedure the skin is covered with Prilocaine cream (EMLA). The first dermatological fractional laser, which was introduced in 2004, was non-ablative Fraxel SR 750, $1540 \mathrm{~nm}$, currently replaced by the higher power Fraxel SR 1500 that is capable of achieving greater penetration. Currently, erbium glass lasers 1540-1550 nm (Fraxel, Mosaic, etc.), which can create columns of controlled overheating at the depth of about $1 \mathrm{~mm}$ without vaporization or breaking the skin surface integrity 


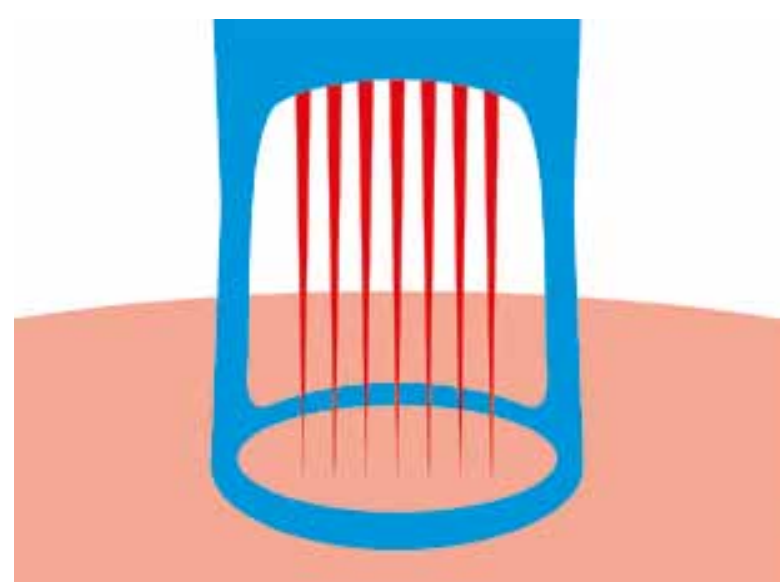

Fig. 1. Columns of fractional laser beams

are used in fractional technology for non-ablative skin rejuvenation.

Ablative Erb-YAG $2940 \mathrm{~nm}$ and CO, $10600 \mathrm{~nm}$ lasers are characterized by forming column skin vaporization areas of - depending on the impulse energy set - up to approximately $90 \mu \mathrm{m}$ and $2.5 \mathrm{~mm}$ in depth in the case of Erb-YAG and $\mathrm{CO}_{2}$ lasers, respectively, which makes it possible to reduce large wrinkles. A new trend aimed at intensification of therapeutic effects in as short a time as possible is to use two lasers during one session, e.g., a deep penetrating $\mathrm{CO}_{2}(10600 \mathrm{~nm})$ laser and Erb-YAG

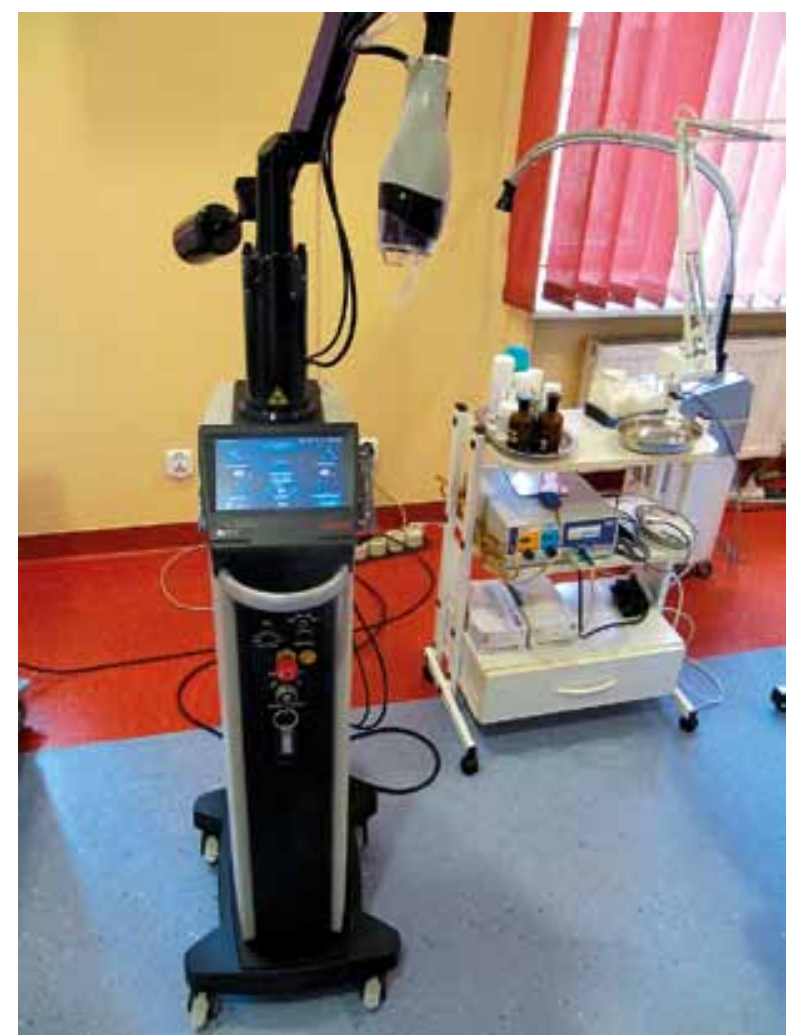

Fig. 3. $10600 \mathrm{~nm} \mathrm{CO}_{2}$ fractional ablative laser

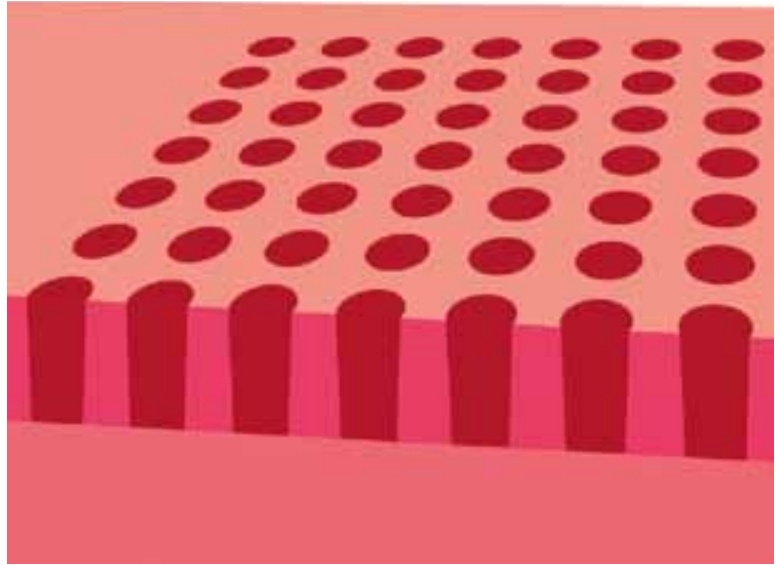

Fig. 2. The picture of the skin. Necrotic columns in case of ablative fractional laser use

(2940 nm) laser operating on the surface or a non-ablative $(1550 \mathrm{~nm})$ laser and Erb-YAG $(2940 \mathrm{~nm})$ ablative laser [3, 5-7] (Figs. 3 and 4).

Qualifying a patient for a given type of procedure includes considering the degree of skin aging symptoms, the patient's expectations and therapeutic possibilities, which depend on the equipment available. Information on the possible side effects of laser therapy with the absolute need of SPF 50 photo protection seems extremely important. Pregnancy, active infectious lesions (e.g. herpes, mycosis), active neoplastic disease, psoriasis

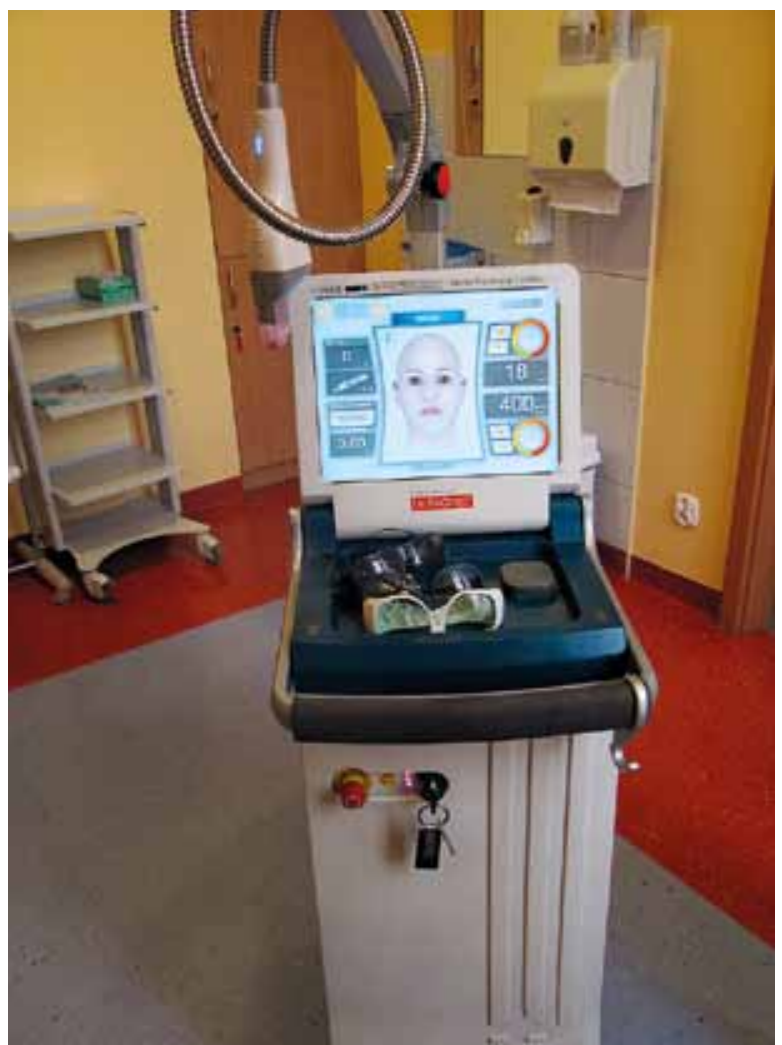

Fig. 4. $1550 \mathrm{~nm}$ erbium glass non-ablative fractional laser (Mosaic) 
and lichen planus (active phase of the disease), proneness to scarring, use of phototoxic substances, treatment with retinoid drugs (less than 6 months following the end of treatment), tanning (approximately 8 weeks following the exposure to UV radiation), epilepsy (in the case of procedures using visible spectrum waves, i.e. 400-780 nm), mental diseases that limit the possibility of giving informed consent to the procedure and unreal expectations are contraindications to the procedure [5].

A patient should be informed about possible results of the procedures and should be aware of the fact that no laser treatment or any other methods can stop time.

The Glogau Classification of Photoaging is usually used to assess the degree of skin aging.

Grade 1 - minimal wrinkles, particularly around the eyes and lips. The wrinkles appear during movements of the facial muscles and the skin. Such lesions are characteristic of the skin of thirty-year-old people.

Grade 2 - mild pigment changes appear, telangiectasias occur, wrinkles are more visible and can be noticed independently of facial muscle movements - wrinkles at rest.

Grade 3 - characteristic features also include gravitational changes; loss of skin firmness and proper tension are visible, the skin gets more flabby compared to the previous grade.

Grade 4 - numerous wrinkles visible. Gravitational changes and photoaging occur; the skin is flabby, thin, dry, devoid of firmness; spots of skin discolorations are present.

We present a 47-year-old patient treated twice a year with $532 \mathrm{~nm}$ KTP laser for three years due to numerous facial telangiectasias. She was qualified for treatment with fractional $\mathrm{CO}_{2}$ laser due to skin discolorations and visible wrinkles occurring mostly around the eyes. Three procedures were performed in 4- 6 week intervals. The energy of $35 \mathrm{~mJ}$ and density of $100 \mathrm{ab}$ lation columns of $300 \mu \mathrm{m} \times 1 \mathrm{~cm}^{2}$ were applied. The area of the procedure was covered with EMLA anes-

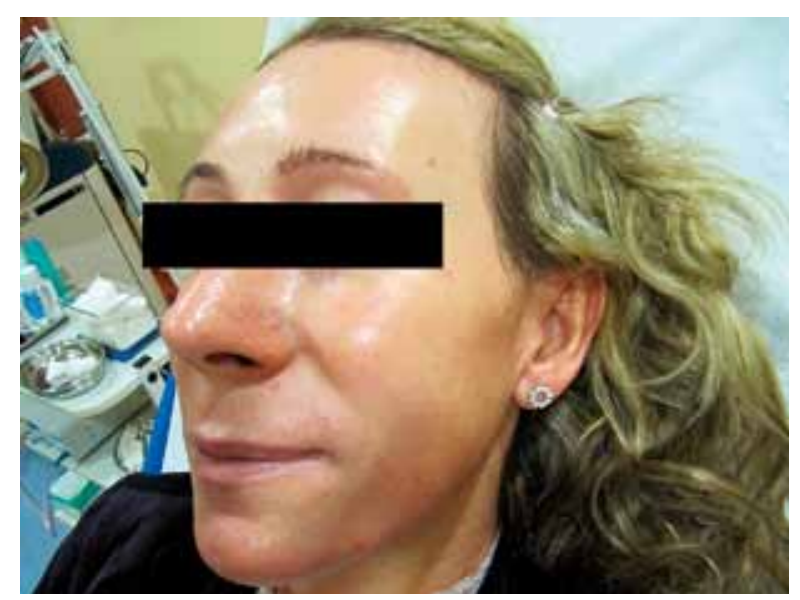

Fig. 5. A 47-year old patient before the first procedure using fractional $\mathrm{CO}_{2}$ laser thetic cream 30-40 minutes before the treatment. The patient tolerated the procedures well, with minimal discomfort, and the healing was without complications. Self-limiting scattered bleeding occurred on the second day after the procedure, about the possibility of which the patient had been informed. During the period after the treatment she was administered preventive external therapy for 7 days, creams accelerating skin healing subsequently and general antibiotic therapy for 5 days. A prophylactic cream with UV SPF 50 was used between the procedures and 30 days after the last procedure and it was recommended to prolong the treatment for the period of increased exposure to sun in order to prevent skin discoloration. Laser treatment resulted in harmonization of the skin color, increased flexibility and a significant reduction of wrinkles, which reduced the effects of skin aging from degree 3 to 2 in the Glogau classification (Figs. 5-8).

Due to the idea of fractionality a part of skin in columns and their direct surrounding is only remodeled with each procedure. Several procedures, usually 3-5 in 4-week intervals, must be performed to optimize the effect and rebuild the whole skin. Skin smoothing is often visible directly after the treatment, which is connected partially with tissue edema. Remodeling of the collagen and improvement in the skin smoothness take place during several months after the procedure and the long-term results can be evaluated afterwards. The period of healing and the risk of undesired effects such as scarring, discoloration, depigmentation or infections have been significantly reduced by introducing the fractional technology. Local treatment with antibiotic creams or silver sulfadiazine are applied until the skin is fully healed, especially after ablative procedures to minimize the risk of possible complications. After nonablative procedures treatment with creams accelerating skin healing is usually sufficient. Photo protection with SPF 50 should absolutely be applied for 4 weeks following the procedure, regardless of its type. Preven-

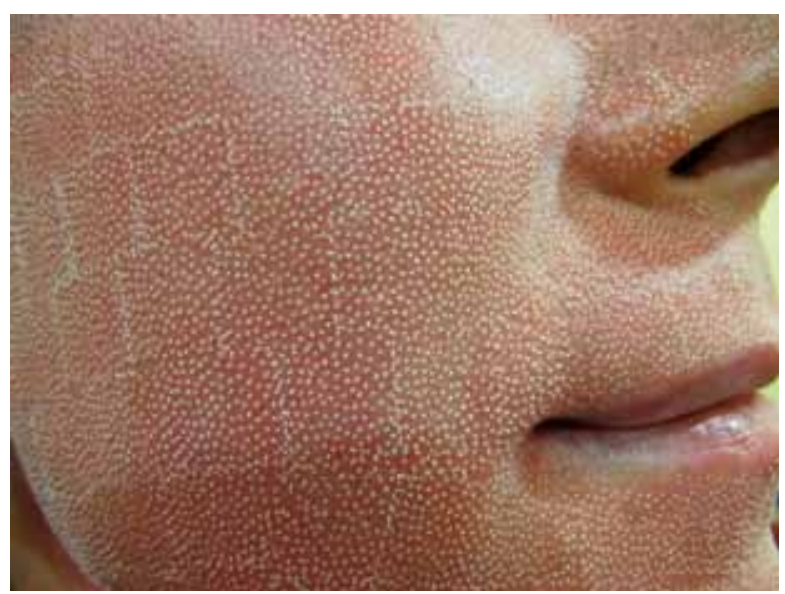

Fig. 6. The same patient directly after $\mathrm{CO}_{2}$ fractional laser treatment 


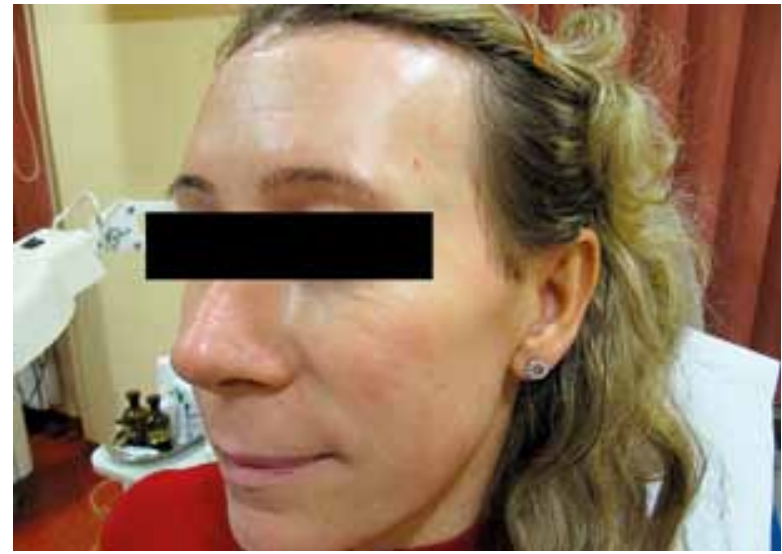

Fig. 7. The same patient before the second $\mathrm{CO}_{2}$ fractional laser treatment

tive antibiotic therapy and treatment for Herpes $\mathrm{S}$ virus are introduced after extensive ablative procedures. After non-ablative procedures, the post-treatment period is usually uncomplicated and healing faster (so-called lunch time treatment). Therefore, it is more frequently chosen by patients who cannot be excluded from their professional life even for several days. The ablative procedure involves a longer healing period due to scattered vaporization of the epidermis (Erb-YAG laser) and creation of necrotic columns ( $\mathrm{CO}_{2}$ laser). Scattered bleeding can occur and the period of re-epithelization coming from the undamaged areas takes 1-2 days, compared to 7-10 days after non-fractional non-ablative procedures. Subsequently, the skin becomes remodeled, with the activated fibroblasts forming new collagen and filling the microscopic column defects [6-9].

Aging is a progressive phenomenon, which still can be alleviated and delayed by systemic or local use of estrogens in women. These improve the nourishment of the skin, which contains a large number of estrogen receptors $[1,2]$.

Apart from hormone therapy, which is applied in the menopausal period and is usually recommended for other reasons than skin aging, fractional laser therapy can be conducted, which at present makes it possible to induce natural processes of tissue regeneration leading to remodeling the aging skin with minimum traumatization. As a result, skin tension improves, the skin sur-

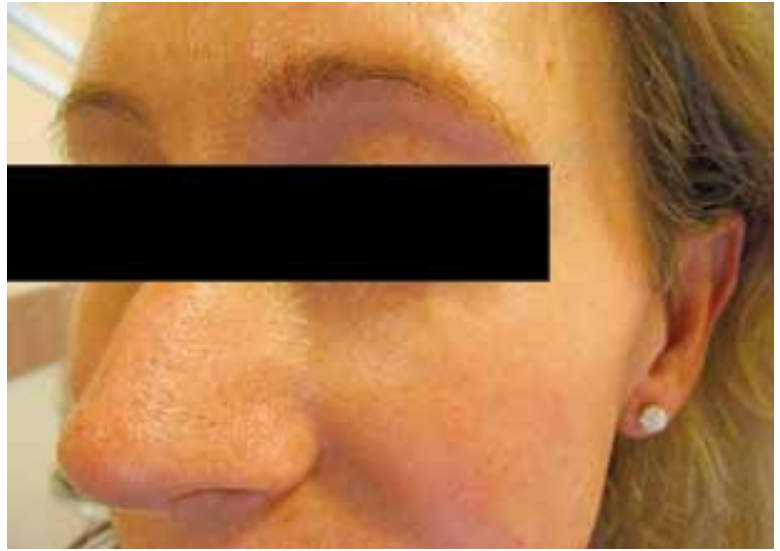

Fig. 8. The same patient one month after three $\mathrm{CO}_{2}$ fractional laser procedures (skin smoothing, wrinkles reversed)

face becomes smoother and the color uniform, which on the whole creates the image of so-called photorejuvenation.

\section{Disclosure}

The authors report no conflict of interest.

\section{References}

1. Trznadel-Budźko E, Rotsztejn H. Wpływ hormonów na procesy starzenia się skóry. Prz Menopauz 2007; 6: 381-383.

2. Trznadel-Budźko E, Rotsztejn H. Dermatologiczne aspekty menopauzy. Prz Menopauz 2006; 6: 398-401.

3. Manstein D, Herron GH, Sink RK, et al. Fractional Photothermolysis: A New Concept for Cutaneous Remodeling Using Microscopic Patterns of Thermal Injury. Lasers Surg Med 2004; 34: 426-438.

4. Anderson R, Parrish J. Selective photothermolysis: precise microsurgery by selective absorption of pulsed radiation. Science 1983; 220: 524-527.

5. Halbina A, Trznadel-Budźko E, Rotsztejn H. Zastosowanie laseroterapii w łagodzeniu objawów starzenia skóry 2010; 3: 190-193.

6. Sherling M, Friedman PM, Adrian R, et al. Consensus recommendations on the use of an erbium-doped 1,550-nm fractionated laser and its applications in dermatologic laser surgery. Dermatol Surg 2010; 36: 461-469.

7. Lapidoth M, Yagima Odo ME, Odo LM. Novel use of erbium:YAG (2,940$\mathrm{nm}$ ) laser for fractional ablative photothermolysis in the treatment of photodamaged facial skin: a pilot study. Dermatol Surg 2008; 34: 1048-1053.

8. Hantash BM, Mahmood MB. Fractional photothermolysis: a novel aesthetic laser surgery modality. Dermatol Surg 2007; 33: 525-534.

9. Butani A, Dudelzak J, Goldberg JD. Recent advances In laser dermatology. J Cosmet Laser Ther 2009; 11: 2-10. 